\title{
O PROJETO "PRIMEIRO, APRENDER!" E A DISCIPLINA HISTÓRIA NO ENSINO MÉDIO DO CEARÁ (2008-2014)
}

\author{
THE "FIRST, LEARN!" PROJECT AND THE SUBJECT OF HISTORY IN \\ SECONDARY SCHOOL IN CEARÁ, BRAZIL (2008-2014)
}

\author{
Isaíde Bandeira da Silva ${ }^{1}$ \\ Décio Gatti Júnior ${ }^{2}$
}

\begin{abstract}
RESUMO: O artigo trata da comunicação de resultados da investigação que teve como objeto o projeto "Primeiro, aprender!", desenvolvido entre 2008 e 2014, com foco na melhoria do Ensino Médio, a partir da iniciativa da Secretaria de Educação do Estado do Ceará. Investigamos, particularmente, a autoria, a abordagem histórico-metodológica e os usos escolares do material instrucional produzido no âmbito do projeto. Os fundamentos teóricos da análise foram buscados em Certeau (1998), Chartier (1990), Chervel (1990), Freire (1998, 2001) e Thompson (1981). Houve pesquisa bibliográfica, com consulta aos parâmetros e as diretrizes curriculares nacionais do Ensino Médio, mas, também, aos documentos oficiais relacionados ao "Primeiro, aprender!" no Estado do Ceará. Além disso, houve entrevistas aos autores do material instrucional e aos professores responsáveis por sua implantação. Os resultados apontaram grandes dificuldades na concepção e na implantação do mesmo, com consequências importantes para a análise de projetos desta natureza no âmbito das políticas públicas de educação no Brasil.
\end{abstract}

Palavras-chave: Ensino médio. Ensino de história. "Primeiro, aprender!". Ceará.

ABSTRACT: This paper communicates results of investigation concerning the project "First, learn!" ("Primeiro, aprender!"). This project was developed from 2008 to 2014 with a focus on improving secondary school education through the initiative of the Department of Education of the state of Ceará, Brazil. Particularly, we have investigated the authorship, the historical-methodological approach, and the educational use of instructional material produced in the sphere of this project. The theoretical foundations of analysis were based on Certeau (1998), Chartier (1990), Chervel (1990), Freire (1998, 2001), and Thompson (1981). Bibliographical research was undertaken, including consultation of the Brazilian national parameters and curricular guidelines for secondary education, but also of the official documents related to the project in the state of Ceará. In addition, the authors of the instructional material and the teachers responsible for its implementation were interviewed. The results indicated great difficulties in conception and

\footnotetext{
1 Professora do Curso de História da Universidade Estadual do Ceará e professora colaboradora do Mestrado Profissional em História da Universidade do Cariri. Doutora em Educação pela Universidade Federal do Rio Grande do Norte

2 Professor Titular de História da Educação da Faculdade de Educação da Universidade Federal de Uberlândia. Doutor em Educação: História e Filosofia da Educação pela Pontifícia Universidade Católica de São Paulo.
} 
implementation of the project, and this had important consequences for analysis of projects of this nature in the sphere of public education policy in Brazil.

Keywords: Secondary school. Teaching history. "Primeiro, aprender!". Ceará.

\section{Introdução}

Este texto comunica os resultados de pesquisa do projeto "Primeiro, aprender!", no qual buscamos compreender sua concepção, processo de elaboração e implantação, com destaque para o material instrucional, em especial, para a forma de abordagem do conteúdo vinculado à disciplina de História.

Em termos de recorte temporal, consideramos como ponto de partida o ano de 2008, quando houve a aprovação de legislação estadual que regulou a implantação do projeto. O ponto de chegada foi estabelecido em 2014, quando o projeto foi finalizado oficialmente.

Utilizamos como suporte teórico Chervel (1990), com o conceito de disciplina escolar; Certeau (1998), com os conceitos de "táticas" e "estratégias"; Chartier (1990), com o conceito de "apropriação"; Freire (1998, 2001), com relação ao conceito de "leitura"; e Thompson (1981), com o conceito de "experiência", que se constrói nas relações sociais. Dialogamos, além destes, com outros autores que trabalham os elementos constituintes das problemáticas relativas ao Ensino Médio, ao Ensino de História e ao uso dos materiais pedagógicos na cultura escolar.

A metodologia da investigação envolveu pesquisa bibliográfica e documental, com destaque para o exame do conteúdo dos Parâmetros Curriculares Nacionais do Ensino Médio (PCNEM), das Diretrizes Curriculares do Ensino Médio (DCNEM), das Orientações Curriculares para o Ensino Médio e dos documentos do Governo do Estado do Ceará relacionados ao projeto "Primeiro, aprender!". (BRASIL, 2002, 2008). 
Também houve entrevistas a três autores, sendo que um deles foi coordenador geral do projeto. Também foram entrevistados sete professores da rede estadual de ensino, de diferentes municípios cearenses, que, assim, estão identificados: professores, de P1 a P7; autores, de $\mathrm{A} 1$ a $\mathrm{A} 3$. Quando o conteúdo da entrevista se referiu às funções do Coordenador Geral do Projeto, a sigla utilizada foi CGP3.

$\mathrm{O}$ texto do artigo está dividido em três partes. Na primeira, abordamos, sucintamente, as diretrizes para o Ensino Médio no Brasil e no Estado do Ceará. Em seguida, trouxemos informações básicas sobre o "Primeiro, aprender!". Na terceira parte, abordamos a situação da disciplina História no âmbito do projeto. Ao final, tecemos algumas considerações sobre o "Primeiro, aprender".

\section{O Ensino Médio Nacional e a Educação Pública no Estado do Ceará}

A universalização do Ensino Médio é relativamente recente no Brasil, pois este foi incorporado à Educação Básica, por meio da Lei de Diretrizes e Bases da Educação Nacional (LDB), em 1996. De acordo com o Artigo 35 da LDB, O Ensino Médio, com duração mínima de três anos, tem como finalidades:

I - a consolidação e o aprofundamento dos conhecimentos adquiridos no ensino fundamental, possibilitando 0 prosseguimento de estudos;

II - a preparação básica para o trabalho e a cidadania do educando, para continuar aprendendo, de modo a ser capaz de se adaptar com flexibilidade a novas condições de ocupação ou aperfeiçoamento posteriores;

III - o aprimoramento do educando como pessoa humana, incluindo a formação ética e o desenvolvimento da autonomia intelectual e do pensamento crítico;

\footnotetext{
${ }^{3}$ No que se refere aos professores entrevistados, seis eram licenciados em História e um em Filosofia, com a quase totalidade tendo realizado cursos de pós-graduação e com experiência no magistério. Quanto aos autores entrevistados, dois eram licenciados em História e um em Filosofia, com titulação em nível de mestrado e de doutorado e com experiência no magistério da Educação Básica e vinculação profissional ao Ensino Superior, bem como com tradição de participação em movimentos de reivindicação relacionados à melhoria da Educação.
} 
IV - a compreensão dos fundamentos científico-tecnológicos dos processos produtivos, relacionando a teoria com a prática, no ensino de cada disciplina. (BRASIL, 1996)

No que se refere ao público do Ensino Médio no Brasil, constatou-se que "dos alunos que frequentam a educação média, 75\% o fazem no período noturno e, dentre esses, 86\% são estudantes trabalhadores" (FRANCO, 1994, p. 120). Nesta direção, em um documento do Ministério da Educação brasileiro, podemos ler a seguinte afirmação:

[...] o aluno do ensino médio se encontra numa situação sociocultural particular a que os cientistas sociais vêm denominando condição juvenil. No caso das redes públicas, acrescentam-se a essa condição algumas determinações relativas a estrato social. Assim como no ensino fundamental, boa parte desse alunado é egressa de camadas populares, com todas as implicações sociais e culturais decorrentes. No entanto, o fato de esse jovem já ter concluído o ensino fundamental e, de além disso, poder manter-se nos estudos, mesmo quando já inserido no mercado de trabalho, Ihe confere um status diferenciado. E o torna objeto de expectativas sociais específicas, a começar pelo papel de "indicador de qualificação" conferido à escolaridade média por toda uma gama de trabalhos, ofícios e profissões.Nesse sentido, aqueles conhecimentos que costumamos definir como "o essencial que um aluno de ensino médio deve saber" - objeto, por sua vez, de inquietações como as que se manifestam no ENEM e nos vestibulares - representam uma outra evidência do valor socialmente atribuído a esse nível de escolarização (BRASIL, 2013, p. 37).

Nesta temática ainda, Knauss (2011, p. 201) afirma que, "[...] os alunos do Ensino Médio devem ser percebidos como cidadãos, não tão jovens, economicamente ativos e inseridos no mercado de trabalho. Isso evidencia o desafio posto ao sistema para garantir o ensino aos jovens brasileiros em igualdade de oportunidades."

No Ceará, conforme dados de 2006 acerca do Sistema de Avaliação da Educação Básica (SAEB) e do Sistema Permanente de Avaliação da Educação Básica (SPAECE) ${ }^{4}$, os jovens que ingressavam no Ensino Médio

\footnotetext{
${ }^{4}$ Desde 1992, existe, no Estado do Ceará, o Sistema Permanente de Avaliação da Educação Básica (Spaece), com a finalidade de monitorar os níveis de aprendizagem dos alunos da Educação Básica, com o intuito de oferecer subsídios para o desenvolvimento de políticas educacionais. Para mais informações consulte 0 site: http://www.seduc.ce.gov.br/index.php/avaliacao-educacional/5170-spaece.
} 
tinham nível de leitura e compreensão que era esperado para os alunos do $5^{\circ}$ ano do Ensino Fundamental, conforme depreende-se do texto a seguir:

Os resultados de Língua Portuguesa e Matemática do Sistema Permanente de Avaliação da Educação Básica - SPAECE, correspondente ao ano de 2006, revelaram a manutenção de uma preocupante situação a respeito dos níveis de competências e habilidades dos alunos das Escolas Públicas em nosso Estado, tanto do Ensino Fundamental quanto do Ensino Médio. Numa Escala de Desempenho de 0 (zero) a 500 (quinhentos), em Língua Portuguesa, 22,89\% dos alunos de $8^{a}$ série evidenciaram - no SPAECE 2006 - um desempenho que os situam no nível 200 da referida escala, enquanto $39 \%$ dos mesmos estão abaixo deste nível. Isso significa que quase $62 \%$ dos alunos egressos do Ensino Fundamental se situam, em termos de competência em Língua Portuguesa, num nível desejável para a $4^{a}$. série do EF (que é o nível 200 da referida Escala de Desempenho). Na verdade, apenas 5,22\% situam-se no nível desejável para os alunos de $8^{a}$. série, o nível 275. Em Matemática, embora a Escala de Desempenho tenha outros valores, os resultados são qualitativamente aproximados: $55,96 \%$ dos alunos estão abaixo do nível 225 da média geral da série, e apenas $21,5 \%$ situam-se nesse nível (CEARÁ, 2008a, p. 11).

Diante deste quadro preocupante, o presidente do Conselho Estadual de Educação do Ceará (CEE), Prof. Edgar Linhares, e a Secretária Estadual de Educação do Estado (SEDUC), Profa. Isolda Cela, resolveram buscar a realização de uma intervenção pontual nos primeiros meses do $1^{0}$ ano do Ensino Médio nas escolas públicas estaduais do Estado do Ceará. Em termos legais, o marco foi a Lei Estadual 14.190/2008, de 30 de julho de 2008, na qual foi instituído o Programa "Aprender pra valer" e o projeto "Primeiro, aprender!", sendo que este último foi uma das principais estratégias da SEDUC para superar os baixos índices de leitura dos alunos ingressantes no Ensino Médio (CEARÁ, 2008a).

\section{O Projeto "Primeiro, Aprender!"}

No decorrer do ano de 2007, houve reuniões no CEE com professores convidados, com o objetivo de traçar os contornos da intervenção pretendida. Nesse sentido, um dos convidados destacou: "o que me levou a 
aceitar o convite é que sou professor e gosto de ser professor. [...] eu queria participar dessa discussão" (CGP). Outro entrevistado salientou que

No primeiro momento, o chamado do Conselho de Educação era muito interessante, pois pensei como uma possibilidade de uma intervenção positiva, contribuir para transformação da Educação Básica, até por conhecer as condições da Educação Básica, como aluno que fui da escola pública e, como docente, considero incontestável a necessidade de mudança na estrutura educacional da Educação Básica (A2).

Segundo os dirigentes da SEDUC era pertinente a proposta do CEE, pois esta realidade já vinha se revelando em avaliações externas realizadas em anos anteriores, tal como apresentado em um estudo de 2005, no qual salientava que "necessário se faz[ia] definir medidas de intervenção, na perspectiva de aproximar o real do desejado ou do necessário para que alcancemos melhores resultados nas avaliações de sistema, a exemplo do SAEB" (VIDAL et al., 2005, p. 63).

Nesta perspectiva, foi criado o projeto "Primeiro, aprender!", sob o lema "Ler bem para aprender pra valer", que, segundo consta no item II do Art. 30. da Lei 14.190/2008, de 30 de julho de 2008 "consiste na consolidação de competências avançadas de leitura e de raciocínio lógicomatemático, utilizando materiais complementares de ensino-aprendizagem especialmente elaborados para este fim" (CEARÁ, 2008a).

O Projeto "Primeiro, aprender!" "ganhou vida" com a elaboração de um material estruturado, com base nos descritores dos sistemas de avaliação Programme for International Student Assessment (PISA), SAEB e Spaece, bem como nas matrizes curriculares estabelecidas para o Ensino Médio, com o intuito de consolidar competências e habilidades básicas para a formação de leitores. A primeira edição do material instrucional relacionado ao projeto "Primeiro, aprender!", publicada em 2008, foi financiada pelo Ministério da Educação (MEC)/Fundo Nacional de Desenvolvimento da Educação (FNDE). A partir de 2009, a segunda edição e as reimpressões passaram a ser financiadas pelo Plano de Ações Articuladas (PAR) do MEC/FNDE.

O material estruturado elaborado era denominado, respectivamente, de "Caderno do Aluno" e de "Caderno do Professor", divididas em dois 
blocos de disciplinas: eixo da Língua Portuguesa (que, além desta disciplina, incluía História, Filosofia, Arte, Educação Física e Inglês) e o eixo da Matemática (que incluía esta disciplina, além de Química, Física, Biologia e Geografia). Cada bloco contava três volumes, que corresponderiam à quantidade de meses em que o projeto seria desenvolvido.

De acordo com os autores entrevistados, o tempo atribuído para desenvolver concretamente o material para chegar às escolas foi exíguo, de janeiro a março de 2008, o que parece ter sido a razão de tantas falhas, constatadas depois e revistas na $2^{a}$ edição.

Eles salientaram dificuldades no processo de concepção e elaboração do material do projeto, dentre elas, questões de ordem burocrática e prática, tais como, "o tempo de elaboração do Projeto, que foi muito corrido, [...] limitação na utilização de imagens, número de páginas e até séria dificuldade quanto à utilização total do número de palavras a cada capítulo" (A1).

O próprio coordenador geral salientou ter havido "[...] muita resistência dos professores elaboradores frente a esta pressão do tempo" (CGP). Havia, também, por parte dos técnicos da SEDUC que acompanhavam as equipes de professores, uma cobrança para que os exercícios não fossem complexos. Conforme um dos autores que entrevistamos, os técnicos da SEDUC faziam questão de salientar que "os estudantes tinham um nível de leitura bem incipiente e não sabiam sequer interpretar as informações que estavam nos livros didáticos" (A2). 
Figuras 1 e 2 - Capas dos Cadernos do Projeto "Primeiro, aprender!". Respectivamente capa do Caderno do Aluno e capa do Caderno do Professor. Material em espiral, com 160 páginas cada um. 1a. Edição.
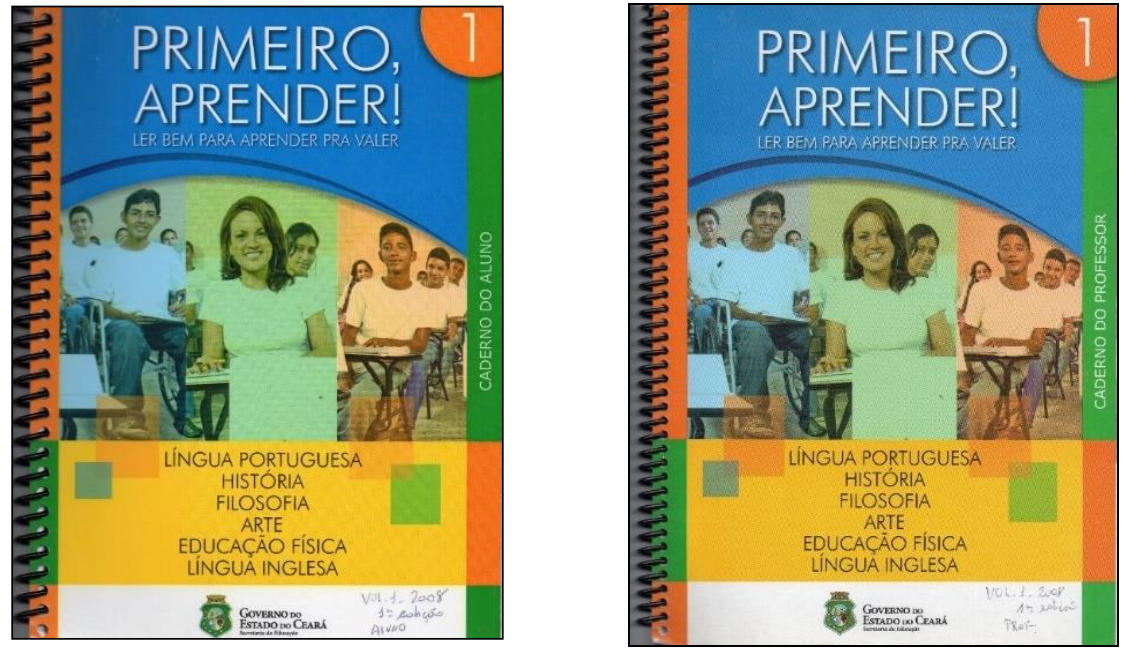

Fonte: Ceará (2008b).

Os Cadernos do Aluno foram compostos por capítulos em forma de aulas (cada capítulo com duas aulas), apresentadas mediante textos-base, sob os mais diferentes suportes, e uma variedade de atividades seguindo uma opção didático-metodológica, do mais simples ao mais complexo. Utilizaram-se vários tipos de documentos como listas, formulários, gráficos e diagramas, além de sugestões de livros, filmes e sites, visando proporcionar experiências prazerosas e enriquecedoras de leitura. Eram consumíveis, portanto o aluno poderia interagir diretamente com o material. De acordo com o coordenador do Projeto: "[...] da Matemática à Filosofia, toda matéria no $1^{\circ}$. ano do Ensino Médio seria voltada para a leitura. Da linguagem simbólica à conceitualização, voltada para a compreensão do processo" (CGP).

No Caderno do Professor, as explicações metodológicas das aulas tinham as competências e habilidades a serem desenvolvidas, bem como algumas sugestões metodológicas e os comentários das atividades salientando o nível de proficiência de cada questão com os conhecimentos/conteúdos envolvidos, além das explicações das possíveis respostas. Para os autores do material do "Primeiro, aprender!", era fundamental que os professores intensificassem a capacidade leitora e o raciocínio lógico dos alunos para além da decodificação das letras, por exemplo, por meio do estímulo à 
interpretação, exercitando a competência linguística, promovendo junto aos alunos o conhecimento da forma de melhor se comunicar por meio dos códigos de nossa gramática normativa.

No ano de implantação do Projeto, 2008, houve seminários com professores representantes das Coordenadorias Regionais (Credes), além da apresentação e distribuição de um vídeo produzido pelos autores dos Cadernos. Contudo, estas ações, coordenadas pelos técnicos da SEDUC, se limitaram ao primeiro ano de execução da proposta, ficando a divulgação do Projeto, nos anos subsequentes, sob a responsabilidade das CREDES e dos gestores escolares.

A primeira edição do material do Projeto "Primeiro, aprender!" apresentava problemas de digitação, repetições de temas e erros nos comentários das atividades. Em pesquisa realizada com análise dos módulos de Língua Portuguesa, a autora chegou à seguinte conclusão: "[...] o material é muito pobre, desatualizado e apresenta sérios erros de coerência, pois apresenta nos textos-base e nas atividades uma série de incongruências que impossibilitam que o objetivo do projeto seja alcançado" (DODÓ, 2014, p. 24).

Apesar desta importante conclusão, não podemos desconsiderar que apenas a partir do trabalho a ser desenvolvido pelos professores é que de fato poder-se-ia avaliar o potencial do material, pois, como nos lembra Chartier (1990, p. 26), os "[...] textos não são depositados nos objectos, manuscritos ou impressos, que o suportam como em receptáculos, e não se inscrevem no leitor como o fariam em cera mole."

Com o objetivo de minimizar as críticas e avaliar a aplicabilidade do projeto no cotidiano das escolas, a Seduc, por meio da coordenação geral do projeto, efetivou encontros regionais nas Credes com representantes dos professores de todas as disciplinas, e chegou à necessidade de reestruturar o material para elaborar a $2^{a}$ edição.

Houve um encontro mais significativo em Fortaleza, em setembro de 2008, do qual participaram 400 professores representantes, com o intuito de revisar e ampliar esse material, a fim de encaminhar a confecção da $2^{a}$ edição. 
Logo no texto de introdução desta $2^{a}$ edição, percebemos algumas mudanças conceituais. Ocorreu a substituição do termo "intervenção", presente na $1^{a}$ edição, por "desenvolvimento de uma ação específica", em negrito. Ocorreu, também, mudança do tempo de aplicação do Projeto, pois na $1^{a}$ Edição, afirmava "três meses de execução" (CEARÁ, 2008b, p. 12); já na $2^{a}$ edição, o texto foi modificado, salientando como tempo médio de execução "quatro meses e meio" (CEARÁ, 2009b, p. 12).

Portanto, a partir da $2^{a}$ edição, o material do Projeto "Primeiro, aprender!" deveria ser trabalhado no decorrer do primeiro semestre do 10 ano do Ensino Médio, o que, consequentemente, gerou o aumento do número de aulas previstas para execução do projeto. Por exemplo, na disciplina de História, passou-se de 24 aulas da $1^{\text {a }}$ Edição, para 36 aulas na $2^{a}$ edição.

De acordo com o coordenador geral do Projeto, houve sensível modificação da $1^{a}$ para a $2^{a}$ edição do material do "Primeiro, aprender!". Contudo, da $3^{a}$ edição em diante, ocorreu apenas a reimpressão do material. Em entrevista, este salientou que:

\begin{abstract}
Nessa $2^{a}$ edição, houve uma melhoria e ampliação do material, inclusive porque os professores participaram do processo. Tivemos melhoria dos textos e questões que apresentavam alguns erros, e a diagramação foi melhor porque formamos nossa equipe de diagramação e não mais da gráfica, e a gráfica foi melhor, porque a que ganhou foi uma gráfica fora do estado com a capacidade imensa. Então, tudo foi melhor mesmo na $2^{a}$. edição. $E$ o processo de revisão foi até 2010, que foi o final da primeira gestão da professora Isolda. Depois foi só reimpressão em 2011 e 2012 $(C G P)$.
\end{abstract}

Em setembro de 2009, houve um encontro avaliativo em Fortaleza com participação de professores representantes das Credes, em que se percebeu que muitas dúvidas e críticas com relação ao projeto ainda precisavam de esclarecimentos, para o que foi confeccionado um suplemento pedagógico para ser enviado às escolas. 


\section{A Disciplina de História no Material do Projeto "Primeiro, Aprender!"}

\subsection{A estrutura da disciplina de História}

Compreendemos o conceito de disciplina, a partir de Chervel (1990, p. 180), como "[...] um modo de disciplinar o espírito, quer dizer de the dar os métodos e as regras para abordar os diferentes domínios do pensamento, do conhecimento e da arte."

Portanto, a História requer um estudo crítico para a aquisição de conhecimentos referentes aos fatos que a constituíram, o que, de acordo com Monteiro (2013, p. 122), "[...] possibilita a desnaturalização deste presente que passa a ser analisado em perspectiva histórica".

A partir destes pressupostos, analisamos como a disciplina de História foi abordada nos três volumes dos Cadernos do projeto "Primeiro, aprender!". Os autores do material de História tomaram a decisão de não abordar fatos históricos específicos, mas sim trabalhar com eixos temáticos e temas de base para a compreensão histórica, a saber:

Com relação às temáticas a serem trabalhadas, nós tivemos uma boa liberdade de escolha. Partimos de práticas de experiências de leitura e escrita e, em cima disso, fomos trabalhando os conteúdos históricos. [...] Então, como era um material para trabalhar a perspectiva da leitura e da escrita, deliberadamente optamos por não trabalhar muito com as exigências curriculares do Ensino Médio, visando atender às matrizes curriculares. Nós não queríamos substituir os livros didáticos ou outros materiais e outras fontes, mas sim trabalhar a leitura e a escrita. Então, toda questão era visando trabalhar com o letramento como foco (A1).

Na $1^{\text {a }}$ edição, eram 24 aulas, distribuídas em 12 semanas, com três eixos temáticos para serem explorados no decorrer das aulas: "Leitura e História", "História e Tempo" e "História e Sociedades, conforme detalhamento exposto no Quadro 1. 
Quadro 1 - Conteúdo do material instrucional de História no projeto "Primeiro, aprender!" (1a. ed., 2008)

\begin{tabular}{|c|c|c|c|}
\hline CAD. & EIXO TEMÁTICO & $\begin{array}{l}\text { AULA } \\
S\end{array}$ & TEMAS \\
\hline \multirow[t]{4}{*}{ VOL.1 } & \multirow[t]{4}{*}{ Leitura e História } & $\begin{array}{l}01 \text { e } \\
02\end{array}$ & Ler é Conhecer o Mundo \\
\hline & & $\begin{array}{l}03 \text { e } \\
04\end{array}$ & Ler é Praticar a Liberdade \\
\hline & & $\begin{array}{l}05 \text { e } \\
06\end{array}$ & Pela Leitura Conhecemos a História \\
\hline & & $\begin{array}{l}07 \mathrm{e} \\
08\end{array}$ & $\begin{array}{l}\text { A Literatura Popular Também é um Registro } \\
\text { Histórico }\end{array}$ \\
\hline \multirow[t]{4}{*}{ VOL.2 } & \multirow[t]{4}{*}{ História e Tempo } & $\begin{array}{l}09 \text { e } \\
10\end{array}$ & Como Lemos o Nosso Tempo \\
\hline & & $\begin{array}{l}11 \mathrm{e} \\
12\end{array}$ & Os Vários Tempos da História \\
\hline & & $\begin{array}{l}13 \text { e } \\
14\end{array}$ & O Tempo e as Suas Durações \\
\hline & & $\begin{array}{l}15 \mathrm{e} \\
16\end{array}$ & Cada História tem seu Tempo Próprio \\
\hline \multirow[t]{4}{*}{ VOL.3 } & \multirow[t]{4}{*}{$\begin{array}{l}\text { História e } \\
\text { Sociedades }\end{array}$} & $\begin{array}{l}17 \text { e } \\
18\end{array}$ & As Sociedades e a História \\
\hline & & $\begin{array}{l}19 \mathrm{e} \\
20\end{array}$ & Das Aldeias às Civilizações \\
\hline & & $\begin{array}{l}21 \text { e } \\
22\end{array}$ & Nossa Herança Africana \\
\hline & & $\begin{array}{l}23 \text { e } \\
24\end{array}$ & Migrações e Fronteiras \\
\hline TOTAL & 12 SEMANAS & $\begin{array}{l}3 \\
\text { MESES }\end{array}$ & 24 AULAS \\
\hline
\end{tabular}

Fonte: Elaborado pelos autores, 2017.

Em cada volume, as aulas foram apresentadas de forma geminada. Todas se iniciam com algumas perguntas para estimular o diálogo; em seguida, existia um pequeno texto-base de uma lauda, permeado com algumas poucas imagens em preto e branco.

Depois, apresentam-se os exercícios, de três a seis questões, que se misturam no grau de dificuldade entre fácil, médio e difícil, com diferentes propostas de atividades, dentre as quais: "caça-palavras"; "cruzadinhas"; "assinalação da alternativa correta"; "argumentação"; "pesquisa em dicionário"; "simulação de júri popular".

Na escrita do material, os autores também utilizaram diferentes fontes e linguagens como, por exemplo, letras de músicas: "Oração ao Tempo" de Caetano Veloso, "Ideologia" de Cazuza; Poesia: "História" de Ferreira Gullar; literatura de cordel: "O profeta popular" de Guilherme Calixto; trechos de 
historiadores, como do italiano Carlo Ginzburg, do livro "Mitos, emblemas e sinais"; dicas de filmes: "Vista minha pele", de Joel Zito, "Che", de Steven Soderberg; mapa; e notícia de jornal.

$\mathrm{Na} 2^{\mathrm{a}}$ edição, observamos um aumento de 12 aulas, totalizando 36 aulas, a serem trabalhadas no decorrer do primeiro semestre letivo do $1^{0}$ ano do Ensino Médio. Assim, as aulas anteriores foram alocadas nos volumes 1 e 2, e surgiu um novo volume 3, com aulas que não existiam na $1^{a}$ edição. Contudo, os eixos temáticos permaneceram os mesmos, mas o terceiro eixo passou a dar enfoque aos temas ligados ao Patrimônio Histórico.

\section{Quadro 2 - Conteúdo do material instrucional de História no projeto "Primeiro, aprender!" (2a. ed., 2009)}

\begin{tabular}{|c|c|c|c|}
\hline CAD. & $\begin{array}{l}\text { EIXO } \\
\text { TEMÁTICO }\end{array}$ & AULAS & TEMAS \\
\hline \multirow[t]{6}{*}{ VOL.1 } & \multirow{6}{*}{$\begin{array}{l}\text { Leitura e } \\
\text { História }\end{array}$} & 01 e 02 & Ler é Conhecer o Mundo \\
\hline & & 03 e 04 & Ler é Praticar a Liberdade \\
\hline & & 05 e 06 & Pela Leitura Conhecemos a História \\
\hline & & 07 e 08 & $\begin{array}{l}\text { A Literatura Popular Também é um Registro } \\
\text { Histórico }\end{array}$ \\
\hline & & 09 e 10 & Ler é Perceber o Tempo \\
\hline & & 11 e 12 & Os Vários Tempos da História \\
\hline \multirow[t]{6}{*}{ VOL.2 } & \multirow{6}{*}{$\begin{array}{l}\text { História e } \\
\text { Tempo }\end{array}$} & 13 e 14 & O Tempo e as Suas Durações \\
\hline & & 15 e 16 & Cada História tem seu Tempo Próprio \\
\hline & & 17 e 18 & As Sociedades e a História \\
\hline & & 19 e 20 & Das Aldeias às Civilizações \\
\hline & & 21 e 22 & Nossa Herança Africana \\
\hline & & 23 e 24 & Migrações e Fronteiras \\
\hline \multirow[t]{6}{*}{ VOL.3 } & \multirow{6}{*}{$\begin{array}{l}\text { História e } \\
\text { Sociedades }\end{array}$} & 25 e 26 & Memória e Sociedade \\
\hline & & 27 e 28 & Patrimônio Histórico Material \\
\hline & & 29 e 30 & Saberes e sabores de Nosso Povo \\
\hline & & 31 e 32 & História e Natureza \\
\hline & & 33 e 34 & A Juventude e a História \\
\hline & & 35 e 36 & História é Vida \\
\hline TOTAL & 18 SEMANAS & $\begin{array}{l}4,5 \\
\text { MESES }\end{array}$ & 36 AULAS \\
\hline
\end{tabular}

Fonte: Elaborado pelos autores, 2016.

O terceiro volume foi o mais elogiado pelos professores que entrevistamos, pois é o volume que abordava de forma consistente a relação entre História e Memória e buscava um desenvolvimento de conteúdos relacionados à Educação Patrimonial.

A despeito do que foi concebido pelos autores para favorecer a construção do pensamento histórico, muitos professores ressaltaram nas 
entrevistas que o material tinha um nível demasiadamente elementar. Como lembra um de nossos entrevistados: "era só o 'burburinho' dos colegas da área reclamando do material do projeto dizendo que era para os 'meninos' do Fundamental, que não tinha nada de importante" (P2). Outro afirmou "alguns colegas até comentavam que era algo bem rasteiro, mas que alinhava ao discurso de colocar uma base comum através de um nivelamento para depois retornar para o livro didático como um elemento mais complexo" (P6).

De acordo com os autores entrevistados, entretanto, o material foi feito considerando os níveis de competência leitora da maioria dos alunos que ingressavam no Ensino Médio, em 2007. No entanto, os autores revelaram que tinham como perspectiva aumentar o nível de dificuldade do material no decorrer das aulas.

O diálogo era a principal metodologia proposta para trabalhar cada texto-base com suas problemáticas e explorar cada questão dos exercícios, ou seja, mediante uma postura em que não só o professor fala, mas estimula o diálogo entre os membros da turma e escuta, além de ensinar a escutar. Desde modo esperava-se contemplar aquilo que defende Gatti Júnior (2014, p. 488): "[...] estimular vivências em torno de conversações autênticas, nas quais a dimensão dialógica predominasse sobre as monológicas, em que a abertura para o entendimento sobrepusesse o esforço da imposição de ideias."

Para as atividades propostas serem respondidas, cada texto-base precisava ser lido e debatido em sala de aula, e, como afirma Chartier (1990, p. 24), era necessário "compreender a apropriação do texto como uma mediação necessária à constituição e à compreensão de si mesmo". Seria o estímulo fundamental à formação de um cidadão que se apropria de sua realidade e passa a ler o entorno e para além deste, adquirindo as condições necessárias para desenvolver, concretamente, as tão desejadas habilidades de leitura, escrita e raciocínio lógico. Ora, diante do quadro de deficiência leitora revelado pelos exames externos, compreender cada texto-base e, consequentemente, os exercícios, nesta perspectiva dialógica, seria o ideal. 
No material de História do projeto "Primeiro, aprender!", sobressaem atividades que partem do conhecimento prévio dos alunos, na perspectiva de valorizar as experiências vividas. Assim, as atividades que eram tomadas como simples visavam estimular a livre expressão que é antecedida pela formulação de ideias lógicas só possíveis a partir da compreensão histórica. Corroborando esta perspectiva, destacamos parte de um depoimento dos professores entrevistados:

Tinha algumas perguntas que pareciam ser simples, bem diretivas, do cotidiano e alguns alunos se espantavam e indagavam qual a importância disso. Mas as questões chamavam a reflexão deles, para eles se reconhecerem como indivíduos pertencentes da História. Aparentemente pode passar despercebido o elemento de reflexão, mas, quando a gente começava a buscar a narrativa de cada um nas respostas, as diferentes experiências vinham à tona. Mas, construir a sensibilidade com os elementos do conteúdo não é fácil, pois há a questão das avaliações padrões como o SPAECE e depois o ENEM, se perde muito com isso, pois nem todos os alunos estão nas mesmas circunstâncias (P6).

Os autores entrevistados ressaltaram que tinham consciência de que o material do "Primeiro, aprender!" não tinha como meta substituir o livro didático, por isso se sentiram livres para trabalhar com temas históricos e não, especificamente, com fatos históricos que depois seriam estudados. No entanto, esta opção não foi bem compreendida por alguns professores que entrevistamos, os quais inevitavelmente comparavam os Cadernos do Projeto com os livros didáticos e faziam críticas fortes aos primeiros. O livro didático desempenha "[...] este papel central no cotidiano escolar dos alunos há tempos e, no caso brasileiro, por que não mencionar, no exercício profissional dos educadores dos mais diferentes níveis [...]" (GATTI JúNIOR, 2004, p. 26). Então, em vez de ser um material a mais no cotidiano escolar em parceria com o livro didático, o material do Projeto foi visto como um substituto muito frágil do livro didático. E, como o planejamento das aulas no cotidiano escolar, em geral, é feito tendo por base o livro adotado na escola pelo Programa Nacional do Livro Didático (PNLD), muitos professores ficaram sem saber como trabalhar, tendo que deixar este material de lado e usar os Cadernos do "Primeiro, aprender!" 


\section{A divulgação e a recepção do material do projeto "Primeiro, Aprender!"}

As escolas estaduais do Ceará iniciaram o ano de 008 com um material pedagógico novo no cotidiano escolar das turmas do $1^{0}$ ano do Ensino Médio: os Cadernos do projeto "Primeiro, aprender!". A divulgação desse material ocorreu primeiramente em Fortaleza, em um Seminário nos dias 11 e 12 de abril de 2008, com a participação de supervisores das Credes e dos professores de todas as disciplinas de dezenas de escolas do interior e da Capital. Seu objetivo era fazer uma sensibilização acerca do material, ou seja, apresentar, explicar e discutir o material com os professores representantes. A coordenação do projeto apresentou um vídeo explicativo, salientando que as formações posteriores dos professores seriam realizadas nas Credes, com os Professores Coordenadores de Área (PCAs), e estes repassariam as informações para os professores das escolas. Uma de nossas entrevistadas participou deste evento, pois, na época, ela era PCA e atuou como multiplicadora, tendo reconhecido que "por mais que os professores convidados tenham esse compromisso no repasse, a informação no percurso vai se desviando da sua originalidade" (P7).

O efeito multiplicador das informações recebidas pelos professores representantes, via Credes, não aconteceu de forma satisfatória nas escolas e, para muitos professores que tiveram que executar o projeto, os objetivos eram obscuros, tal como se apresenta no depoimento a seguir:

Quando de repente chegaram pilhas e mais pilhas de
apostilas e a coordenadora pedagógica da época disse: 'olha
esse aí é o material que chegou da SEDUC para vocês
usarem com os alunos'. Mas nós não estávamos sabendo
bem o que era esse Projeto "Primeiro, aprender!", as raízes
como eram para ser usado. Cada professor recebeu o
"Manual do Professor" do Projeto entregue pela
coordenadora, mas a gente folheava, mas não entendia
direito o que era para fazer e nos perguntávamos "para que
é isso mesmo?"[...] houve uma confusão em nossa cabeça
como usar, por quanto tempo cada volume do Projeto
"Primeiro, aprender!", ou mesmo se podíamos usar junto
com o livro didático. Não houve esta explicação! (P4).


Um dos autores do material instrucional complementou a observação do professor, pois, para ele:

As intervenções da SEDUC infelizmente são muitas vezes autoritárias, sem a discussão devida. [...] Eu acho que esse quadro de desconfiança em relação às ações da SEDUC somado à forma como o projeto 'Primeiro, aprender!' foi implementado, simplesmente chegando lá e dizendo "olha professor não vai mais usar o livro didático, durante um período você é obrigado a usar o material do projeto 'Primeiro, aprender!', acabou gerando uma certa incompreensão com relação ao material (A2).

Dos sete professores entrevistados, quatro destacaram que o desenvolvimento da competência leitora e de raciocínio lógico dos alunos ingressantes no Ensino Médio eram as justificativas para a implantação do Projeto nas escolas em que trabalhavam. Contudo, informaram que foram procurar os motivos por si, por exemplo no site da Seduc, pois os objetivos não foram claramente expostos pela gestão escolar, o que levou alguns entrevistados a salientarem que este Projeto foi uma "imposição da Seduc" que "chegou de cima para baixo", desrespeitando a realidade e as expectativas das escolas, como a que se fez presente no município de Guaiúba o qual , em 2008, utilizaria o livro de História advindo do PNLD pela primeira vez, visto como uma conquista muito pleiteada pelo conjunto dos professores, como ressaltou o professor:

Eu sou de uma geração de professores que militava, advogava mesmo que nós tivéssemos livro didático no Ensino Médio. É tanto que no primeiro processo de escolha do livro didático no PNLEM eu fiz questão na CREDE que nós professores de fato tivéssemos autonomia para escolher. [...] quando conseguimos os livros didáticos pelo PNLD, de repente chega o material do Projeto "Primeiro, aprender!" e nós não fomos convidados a falar sobre isso, não fomos participados. Há certa centralização das decisões na SEDUC (P6).

Seria o material do "Primeiro, aprender!" um apoio ao livro didático? Ou substituição do livro didático? De fato, a maioria dos professores entrevistados ressaltou que não houve uma sensibilização sobre a importância do uso dos Cadernos do projeto junto ao livro didático, pelo contrário, a orientação inicial da gestão da escola era para que se fizesse uso exclusivo do material do projeto "Primeiro, aprender!" e os livros 
didáticos fossem deixados de lado. Diante desta orientação, muitos professores tiveram repulsa ao material antes mesmo de conhecê-lo, como podemos depreender por meio dos seguintes depoimentos:

O projeto 'Primeiro, aprender!' da forma como veio, vertical, imposto, com regras a serem cumpridas, não foi bem-vindo de minha parte [...] a orientação era abolir o livro didático (P5). Lembro '- Olha vocês parem as atividades com os livros didáticos e façam uso agora deste material'. Então suspendemos os usos dos livros didáticos (P6).

De acordo com pesquisa desenvolvida por Brito (2012), a Coordenadoria de Desenvolvimento da Escola e Aprendizagem (CODEA) vinculada a SEDUC "compreende que o material do 'Primeiro, Aprender!' é um complemento do livro didático, não compreende que a proposta seja concorrente com o livro, mas que no período de execução do projeto, deve ser utilizado com exclusividade" (BRITO, 2012, p. 48).

A divulgação do material também apresentou falhas na compreensão de alguns professores com relação ao período em que o material seria trabalhado nas turmas do $1^{0}$ ano do Ensino Médio, como podemos observar nos seguintes depoimentos dos entrevistados:

"Havia uma imposição via SEDUC de que o projeto 'Primeiro, aprender!' fosse executado no primeiro mês de aula nas turmas do $1^{0}$ ano do Ensino Médio" (A1). Porém, "[...] quando o material chegava, conseguíamos trabalhar tudo ao longo do ano letivo" (P3).

Um dos pontos negativos salientados pelos professores diz respeito ao atraso na entrega do material do projeto, que era para ser no início do ano letivo. Assim, alguns assuntos já haviam sido trabalhados em sala de aula, conforme planejamento feito na Semana Pedagógica, sendo que algumas escolas já tinham começado a usar o livro didático e a fazer a sensibilização relacionada à participação no Exame Nacional do Ensino Médio (ENEM). O fato se aclara no depoimento do professor, no qual se lê: "Quando os primeiros volumes começaram a chegar, nós já tínhamos terminado o primeiro bimestre do ano letivo e esse atraso atrapalhou o desenvolvimento de alguns assuntos do material" (P3).

Deste modo, um clima de insatisfação se estabeleceu entre muitos dos profissionais da Educação do Estado, que culminou com uma nota de 
repúdio na Assembleia Final do XXV Encontro Nacional da ANPUH, ocorrida em julho de 2009, na Universidade Federal do Ceará, em Fortaleza, a saber: "Manifestou-se o repúdio ao apostilamento dos cursos por secretarias de educação que estariam produzindo materiais didáticos próprios ao invés de recorrer aos livros distribuídos pelo Ministério da Educação" (SIMPÓSIO NACIONAL DE HISTÓRIA, 2009, p. 4). A repercussão dessa Assembleia chegou à SEDUC, a qual reconheceu que muitas perguntas precisavam ser respondidas para melhor execução do Projeto no cotidiano escolar. Um terceiro Encontro com professores representantes ocorreu no dia 21 de setembro de 2009, no Centro de Treinamento da SEDUC, com a equipe elaboradora dos Cadernos do Projeto e alguns professores. Foram solicitadas, pelos representantes dos professores, capacitações para todos os docentes do Estado, com o fim de expor os objetivos do "Primeiro, aprender!", e explicar a metodologia mais adequada de uso do material instrucional.

Como resultado dos encontros avaliativos do projeto, foi elaborado um suplemento de apoio pedagógico confeccionado pela CODEA/SEDUC, explicando "os pontos mais relevantes levantados por diretores escolares e professores a respeito dos módulos estruturados, em encontros de avaliação do Projeto" (CEARÁ, 2009a, p. 1) e enviado para cada escola do Estado.

\section{Os usos do material do projeto "Primeiro, Aprender!": experiências vividas no cotidiano escolar}

De acordo com Certeau (1998), não há consumo passivo, pois, no cotidiano, existem inúmeras maneiras de fazer uso de algo material. Este debate requer uma rearticulação com os conteúdos estabelecidos e, quando possível, a superação da ordem cristalizada destes, no processo constante da disputa, entre táticas e estratégias, pois há "maneiras de fazer" que alteram ou reinventam formas de viver no espaço organizado e pré-fixado, num fazer diferente dentro do oficial; em especial, considerando a diferença entre estratégias e táticas, enquanto aquela pode ser pensada de forma 
institucional, esta se aproveita das brechas. Entre o consumidor e o produto, há usos que podem ser diferentes daqueles pensados pelo produtor.

Para Thompson (1981), a História é um processo que não pode ser engaiolado, pois a História se faz com análise das ações, experiências vividas, e não das ideias a priori, por isso é importante atribuir significados/valores às ações dos diferentes sujeitos e interrogar as evidências. Como também nos lembra Bertucci, Faria filho e Oliveira (2010, p. 56), "[...] as culturas escolares não são um pressuposto, mas sim o processo e o resultado das experiências dos sujeitos, dos sentidos construídos e compartilhados e/ou disputados pelos autores que fazem a escola."

Quando os Cadernos do projeto "Primeiro, aprender!" chegaram às escolas públicas de Ensino Médio, do Estado do Ceará, muitos professores foram pegos de surpresa, pois não haviam sido informados e, muito menos, capacitados para explorar o material como foi pensado pelos autores. Como salientou uma de nossas entrevistadas: ficou "de certa maneira [...] de cada professor fazer o uso que achar apropriado do material." (P4). Como também podemos perceber no depoimento de outro professor que entrevistamos: "a gente sabia que havia ali no "Primeiro, aprender!" uma proposta viável, mas como fazer? Como aplicar? $E$ esta percepção particularmente era minha, eu entendia que havia uma possibilidade de se trabalhar com o material, mas nem eu sabia como fazer" (P2).

A partir dos depoimentos dos professores entrevistados, vislumbramos duas grandes determinações para os usos dos Cadernos do projeto "Primeiro, aprender!", por parte dos gestores escolares: em algumas escolas orientou-se usar exclusivamente o material, enquanto em outras estimulou-se utilizá-lo em concomitância com os livros didáticos. Um dos autores dos Cadernos de História salientou: "A informação que tínhamos era que esse material não iria substituir o livro didático! A ideia 
era mais de adequação/intervenção ali no início do Ensino Médio" (A2). Já o próprio Coordenador Geral do projeto ressaltou:

A ideia inicial era suspender o livro didático, depois se concebeu que poderia ser articulado com o livro didático e depois se compreendeu que as escolas são muito diferentes e ficaria livre para trabalhar de forma associada ou não o material e o livro didático e depois só o livro didático, em algumas situações o livro de apoio ao material e em outras o material de apoio ao livro didático. Isso ia depender da autonomia do professor em sala de aula.

Seja de forma exclusiva ou concomitante com o livro didático, o certo é que havia a obrigatoriedade de pôr em prática o material do Projeto. Todavia, uma pesquisa realizada sobre o papel da gestão escolar frente ao Projeto salientou que, com exceção dos professores de Português e Matemática, "[...] os professores de outras disciplinas resistem em utilizar o material e apenas o fazem como recurso auxiliar, sem seguir a sequência do programa estabelecido pelo material." (BRITO, 2012, p. 34). Esta constatação coaduna-se com o relato de um dos professores de História que foi entrevistado: "não vou mentir, eu tive uma rejeição muito grande a este projeto "Primeiro, aprender!", pois eu também achava infantil e algumas discussões meio deslocadas, embora com algumas temáticas até pertinentes" (P1).

Os Cadernos dos professores, que tinham a finalidade de orientar os usos do material do projeto no cotidiano das aulas, ao que parece, pelos depoimentos dos entrevistados, não eram muito claros e tinham pouca objetividade, como podemos perceber abaixo:

O que eles enviaram para a gente foi um livro de suporte (caderno do professor), que eu dei uma olhada e não compreendi muito bem" (P1). Cada professor recebeu o "Manual do Professor" do projeto entregue pela coordenadora, mas a gente folheava, mas não entendia direito o que era para fazer, e nos perguntávamos "para que é isso mesmo?(P4).

Outra questão inquietante foi que a princípio, em 2008, o Projeto deveria ocupar os três primeiros meses do $1^{0}$ ano do Ensino Médio, na $1^{a}$ edição, e, no primeiro semestre, na $2^{a}$. edição, porém, pelos depoimentos 
que obtivemos nas entrevistas, foi utilizado durante quase todo o ano letivo. Exemplo:

"No primeiro ano de uso do Projeto "Primeiro, aprender!", em 2008 na escola, começamos a usar no mês de maio e fomos até o final do ano com os Cadernos do Projeto" (P5). "Trabalhamos dois volumes quase durante um ano inteiro nas turmas do $1^{\circ}$ ano" (P6).

E ainda em algumas escolas se estendendo até o $2^{\circ}$ ano do Ensino Médio, como no caso de uma da escola do município de Pentecoste:

No primeiro ano do projeto, não deu tempo de chegar ao Caderno 3, e esse caderno foi trabalhado na turma do $2^{\circ}$ no ano seguinte, pois em 2008 não deu para trabalhar [...]. Pense numa aversão que os alunos tiveram, pois já estavam no 20. ano tendo ainda que trabalhar com o material do Projeto "Primeiro, aprender! (P5).

O coordenador geral do Projeto ressaltou que os três volumes eram para ser usados no $1^{0}$ semestre do $1^{0}$ ano do Ensino Médio, mas, em virtude do atraso da entrega do $3^{\circ}$ volume em alguns CREDES, foi orientado que em algumas turmas este volume fosse usado no início do $2^{\circ}$ ano do Ensino Médio.

Outra questão importante quanto ao uso, ou não, dos Cadernos diz respeito ao investimento público para concretizar o Projeto "Primeiro, aprender!", pois seria complicado deixar o material impresso encostado, sem explorá-lo com os alunos, "porque afinal de contas o Estado estava investindo no material, em cima de um diagnóstico que havia sido feito." (P3). Entretanto, em algumas escolas, o material do projeto realmente não foi usado, como por exemplo no Liceu de Messejana, conforme relatou um dos professores entrevistados: "o "Primeiro, aprender!" estava lá na biblioteca como fonte, consulta, mas não era entregue para os alunos, nem com o atraso do livro didático este material do Projeto foi distribuído para os alunos do Liceu" (P2). Nesta linha de abordagem, também é pertinente o relato de uma professora entrevistada:

[...] a gente tinha a responsabilidade de valorizar este investimento em sala de aula, de dar um retorno, pois tudo o que vem do Governo Estadual ou Federal é fruto de nossos impostos, então a gente fazia essa reflexão também com os alunos de que aquele material não era dado, era um investimento $(P 4)$. 
Esta questão do investimento de verbas públicas para compra do material do Projeto "Primeiro, aprender!", cabe também para os livros didáticos que, conforme já abordamos, em algumas escolas foram deixados de lado durante todo o ano escolar para que se usassem apenas o material do Projeto. Neste caso, destacamos duplo prejuízo, primeiro deixar um material como os livros didáticos sem ser usado durante quase todo o ano letivo e, segundo, dificultar aos alunos a aquisição de conteúdos específicos do Ensino Médio.

De modo geral, o turno da noite aceitava bem o material, mas os alunos dos turnos diurnos tinham preconceito com o material, por considerá-lo fraco. Conforme depôs uma de nossas entrevistadas: "Percebemos certo descrédito por parte de alguns alunos, talvez em decorrência do descrédito de alguns professores em não trabalhar o projeto 'Primeiro, aprender!' como deveria. Então o material não foi dando o resultado esperado." (P7).

A despeito das críticas ao material, podemos ressaltar algumas experiências positivas nos usos dos Cadernos do projeto "Primeiro, aprender!" em sala de aula. Como algumas atividades desenvolvidas com o volume 1: nas primeiras aulas, a partir do trabalho desenvolvido pelo professor, alguns alunos se sentiram sujeitos da História; alunos começaram a ter mais coragem de se expressar frente aos assuntos abordados no material; outros conseguiam fazer bem as atividades propostas no material. Por exemplo:

No material do projeto "Primeiro, aprender!" tinha a letra da música do Titãs e isso ficou marcado para mim, pois a escola não tinha equipamento para ouvir a música, e eu levei meu micro system para os alunos puderem ouvir a música. $O$ trabalho com esta música do Titãs me marcou muito" (P6).

Considerando a autonomia do professor em sala de aula, podemos salientar que, em meio às temáticas apresentadas nos Cadernos de História do projeto, algumas mereceram mais destaque pelos professores entrevistados como, por exemplo: "eu gostei demais de trabalhar com os alunos a perspectiva da leitura, e também gostei da aula "Ler é conhecer o tempo! [...] o material traz a literatura de cordel como uma fonte e gostei 
muito" (P5). "Lembro que tinha Paulo Freire citado e eu trabalhava a perspectiva dele" (P6).

É importante salientar, entretanto, que, dos três volumes do material do Projeto "Primeiro, aprender!", o terceiro foi o que mais se destacou de forma positiva nos depoimentos da maioria dos professores entrevistados, 0 que é corroborado pelo fato de que as experiências positivas relacionadas aos usos do material do projeto estão, em geral, atreladas aos usos do Caderno do volume 3, que se refere ao Patrimônio, conforme podemos perceber nos seguintes relatos de nossos entrevistados:

Quando o material do Projeto "Primeiro, aprender!" abordava sobre o patrimônio material e imaterial, eu aproveitava bastante com eles, e considerei esse caderno 3 bem significativo, também porque era uma temática que não vinha nos livros didáticos da forma como o material do Projeto "Primeiro, aprender!" abordou a cultura matéria e imaterial, o patrimônio histórico, memória individual e coletiva $(P 5)$.

Eu achava muito bacana trabalhar com as questões do projeto "Primeiro, aprender!", como o conceito de patrimônio, e neste caso eu já utilizava o espaço da cidade, pois os meninos [alunos] sempre passavam pela igreja sem observá-la e perceber os lugares de memória da cidade. Então, eu partia sempre da vivência deles, do cotidiano, da memória deles. (P7).

O fato é que havia um problema pontual importantíssimo que precisava ser combatido, e não adiantava fingir que essa realidade dizia respeito apenas a uma pequena parcela das escolas públicas estaduais espalhadas pelos municípios cearenses, infelizmente, pelo contrário. Por isso, o coordenador geral do Projeto explicou:

A questão era conscientizar o professor que não adiantava dar aula para três alunos que estavam compreendendo o material, era preciso voltar-se para os 45 alunos, e alguns professores até poderiam perguntar "e o que eu faço com os três?". Mas o problema não são os três! São os 42 alunos que não estão acompanhando a contento a matéria. Então, se o bom pastor deixa o rebanho para salvar aquela ovelha que se perdeu, o bom professor é aquele que "para" 3 para "salvar" (digamos assim) para cuidar de 42 alunos. 0 aluno que já sabe pode exercitar a monitoria, orientação com os colegas. (CGP).

O cenário exposto acima, pelo coordenador geral do Projeto, nos fez lembrar as palavras de Eric Hobsbawn (1998, p. 21), palestrando para 
futuros professores, em uma aula inaugural da Universidade da Europa Central, em Budapeste: "Os que obtêm as melhores notas cuidarão de si mesmos, ainda que seja para eles que você gostará de lecionar. Os outros são os únicos que precisam de você."

\section{Considerações Finais}

É interessante observar que a avaliação de um problema concreto, a dificuldade da maioria dos alunos inressantes no Ensino Médio do Estado do Ceará, detectado por meio de instrumentos objetivos, levou as autoridades governamentais à proposição de um programa e de um projeto que perduraram entre 2008 e 2014. Todavia, apesar das boas intenções presentes no projeto, houve enorme dificuldade na implantação de ações governamentais que pudessem colaborar para superação do problema detectado.

Parece evidente que as dificuldades na concepção e na implantação do projeto "Primeiro, aprender" ultrapassaram os possíveis benefícios para o público que visava atingir, neste caso, os alunos ingressantes do Ensino Médio no Estado do Ceará, o que incluiu: problemas na qualidade do material instrucional, choque com a utilização do livro didático, dificuldade de envolvimento dos professores com a execução do projeto, atraso na entrega do material instrucional etc. Todavia, é preciso tirar de uma experiência como esta um conjunto de conclusões que possa levar os agentes envolvidos para uma atuação futura mais eficiente na resolução de problemas.

Deste modo, parece importante que as ações públicas na melhoria da educação sejam pautadas pela experiência acumulada, bem como pela capacidade de planejamento que leve em consideração a necessidade de desenvolver material instrucional e ações que possam ser testadas antecipadamente e, sobretudo, em pequena escala, por meio de projetos pilotos, nos quais as estratégias e os materiais possam ser avaliados rigorosamente, por uma série de agentes do processo, antes de serem 
estendidos para populações maiores. Além disso, na própria fase de concepção dos projetos de intervenção, parece importante envolver, de modo consistente, os atores que terão que dar vida aos processos relacionados à execução do projeto.

É importante, também, pensar a educação escolar como um todo, sem dissociar o Ensino Médio da fase anterior, o Ensino Fundamental, de modo a viabilizar melhorias no lugar adequado, evitando problemas que se perpetuam por anos seguidos de escolarização. Por fim, é fundamental que os esforços de nivelamento, tal qual foi a tentativa preconizada no âmbito do projeto "Primeiro, aprender!", possam contar com maior sofisticação, com escolha mais cuidadosa dos alunos que necessitam desta intervenção, e que possa ser realizada, senão antes do início das aulas, pelo menos em paralelo às mesmas, ainda que isso possa significar a ampliação dos gastos públicos em educação e, sobretudo, a alteração do tempo escolar, em benefício da melhoria do ensino.

Sem dúvida, esta aprendizagem só se tornou possível pela disposição que uma série de sujeitos preocupados com a qualidade da educação tiveram, movimentando os representantes do povo e uma série de órgãos públicos em torno da resolução de problemas graves. Os resultados, porém, foram tímidos e as dificuldades mostraram-se enormes. Assim, parece muito importante persistir na busca de uma atuação cada vez mais consistente, que aprenda com os erros e consolide práticas mais eficientes e de impacto positivo sobre a qualidade da aprendizagem, por meio da educação escolar.

\section{Referências}

SIMPÓSIO NACIONAL DE HISTÓRIA. História e Ética, 25., 2009, Fortaleza, CE. Ata de encerramento... [manuscrito]. Fortaleza: Associação Nacional de História - ANPUH, Universidade Federal do Ceará-UFC, 2009.

BERTUCCI, Liane Maria; FARIA FILHO, Luciano Mendes de; OLIVEIRA, Marcus Aurélio Taborda de. Edward P. Thompson: história e formação. Belo Horizonte: Ed. da UFMG, 2010. 
BRASIL. Congresso Nacional. Lei 9.394, de 20 de dezembro de 1996. Estabelece as diretrizes e bases da educação nacional. Disponível em: <http://www.planalto.gov.br/ccivil_03/Leis/L9394.htm>. Acesso em: 10 set. 2017.

BRASIL. Ministério da Educação. Fundo Nacional de Desenvolvimento da Educação. Secretaria de Educação Básica. Edital de convocação para o processo de inscrição e avaliação de obras didáticas para o Programa Nacional do Livro Didático: PNLD 2015. Brasília, DF, 2013.

BRASIL. Ministério da Educação. Secretaria de Educação Básica. Orientações Curriculares para o Ensino Médio. Ciências Humanas e suas Tecnologias. Brasília/DF: MEC; SEB, 2008.

BRASIL. Ministério da Educação. Secretaria de Educação Média e Tecnológica. Parâmetros Curriculares Nacionais. Ensino médio. Brasília, 2002.

BRITO, Márcio Pereira de. Projeto "Primeiro, aprender!": estudo de caso em quatro escolas públicas estaduais do Ceará. Dissertação (Mestrado em Gestão e Avaliação em Educação Pública) - Universidade Federal de Juiz de Fora, MG, Juiz de Fora, 2012.

CEARÁ. Secretária da Educação do Estado. Lei 14.190 de 30 de julho de 2008. Cria o Programa "Aprender pra Valer" que desenvolverá ações estratégicas complementares para o fortalecimento da aprendizagem dos alunos do ensino médio e sua articulação com a educação profissional e tecnológica. 2008a. Disponível em:

<http://www.seduc.ce.gov.br/images/Desenvolvimento_da_Escola/lei_1419 0_2008_cria_programa_aprender_pra_valer.pdf>. Acesso em: 10 set. 2017.

CEARÁ. Secretaria da Educação do Estado. Primeiro, aprender! Ler bem para aprender pra valer. Fortaleza, 2009a.

CEARÁ. Secretaria da Educação do Estado. Primeiro, aprender! Língua portuguesa, história filosofia, arte, educação física, Língua inglesa (Caderno do Aluno, 3v., Caderno do Professor, 3v.). Fortaleza, 2008b.

CEARÁ. Secretaria da Educação do Estado. Primeiro, aprender! Língua portuguesa, história filosofia, arte, educação física, Língua inglesa (Caderno do Aluno, 3 v., Caderno do Professor, 3 v.). Fortaleza, 2009b.

CERTEAU, Michel de. A invenção do cotidiano: artes de fazer. Tradução de Ephain Ferreira Alves. 3. ed. Petrópolis: Vozes, 1998.

CHARTIER, Roger. A história cultural: entre práticas e representações. Tradução de Maria Manuela Galhardo. Lisboa: DIFEL, 1990. 
CHERVEL, André. História das disciplinas escolares: reflexões sobre um campo de pesquisa. Teoria \& Educação, Porto Alegre, n. 2, p. 177-229, 1990.

DODÓ, Karla Regina Alves. O ensino pragmático de gramática no ensino médio: uma análise do projeto "Primeiro, aprender!". Quixadá, CE:

Faculdade de Educação, Ciências e Letras do Sertão Central, 2014.

FRANCO, Maria Laura P.B. Ensino médio: desafios e reflexões. Campinas, SP: Papirus, 1994.

FREIRE, Paulo. Pedagogia dos sonhos possíveis. São Paulo: Ed. da UNESP, 2001.

FREIRE, Paulo. Pedagogia da autonomia: saberes necessários à pratica educativa. São Paulo: Cortez, 1998.

GATTI JÚNIOR, Décio. A escrita escolar da História: livro didático e ensino escolar no Brasil (1970 - 1990). Belo Horizonte. EDUSC, 2004.

GATTI JÚNIOR, Décio. Em busca da articulação entre compreensão empática, sensibilidade e dimensão dialógica: contribuições para o ensino da história no Ensino Médio brasileiro. Perspectiva, Florianópolis, v. 32, n. 2, p. 475-495, 2014.

HOBSBAWN, Eric J. Sobre história: ensaios. Tradução de Cid Knipel Moreira. São Paulo: Companhia das Letras, 1998.

KNAUSS, Paulo. Ensino médio, livros didáticos e ensino de História: desafios atuais da educação no Brasil. In: FONSECA, Selva Guimarães; GATTI JÚNIOR, Décio (Org.). Perspectivas do ensino de História: ensino, cidadania e consciência histórica. Uberlândia, MG: EDUFU, 2011. p. 199-215.

MONTEIRO, Ana Maria Ferreira da Costa. Livros didáticos de História para o ensino médio e as orientações oficiais: processos de recontextualização e didatização. In: GALZERANI, Maria Carolina Bovério; BUENO, João Batista Gonçalves; PINTO JúNIOR, Arnaldo (Org.). Paisagens da pesquisa contemporânea sobre o livro didático de história. Jundiaí, SP: Paco; Campinas, SP: Centro de Memória/Unicamp, 2013. p. 209-225.

THOMPSON, Edward Palmer. A miséria da teoria: ou um planetário de erros: uma crítica ao pensamento de Althusser. Tradução de Waltemir Dutra. Rio de Janeiro: Zahar, 1981.

VIDAL, Eloisa Maia et al. O currículo do ensino médio cearense. Fortaleza: SEDUC, 2005. 